\title{
ELIAS TRABULSE
}

\author{
El reloj de Oaxaca \\ Astronomía y cronometría en el \\ México colonial
}

$\mathrm{C}_{\text {en la ciudad de Oaxaca, existe un valioso aunque olvidado }}^{\mathrm{N} \text { el claustro del majestuoso convento de Santo Domingo, }}$ testimonio de la historia de la ciencia en México. Se trata de un reloj de sol construido en el año de 1639 por el científico criollo Diego Rodríguez, miembro de la Orden de la Merced y catedrático de matemáticas en la Real y Pontificia Universidad de México.

Nadie puede negar que la contemplación de un viejo y venerable testigo del pasado, como es ese reloj solar, nos permite evocar épocas en que el tiempo se movía más lentamente, la vida era sin duda menos complicada y era más fácil relajarse y meditar. Adosados a los muros de las iglesias o de las casas, los relojes de sol tienen atractivo único para el historiador que los mira como un símbolo de la caducidad de las cosas y para el científico que los considera como representantes de un momento capital en el desarrollo de la astronomía. Sin embargo la ciencia de estos relojes no ha sido olvidada y hoy en día son numerosas las personas que cultivan la gnomónica, que así se denomina el arte de los relojes de sol.

Estos viejos instrumentos científicos son una especie de intermediarios entre la visible aunque solamente aparente trayectoria del sol y nuestra comprensión indirecta del movimiento real de nuestro planeta. Al ver la sombra de la aguja o gnomon recorrer el cuadrante podemos desde la tierra imaginar al sol en su camino por el firmamento a lo largo de la eclíptica. Se diría incluso que el gnomon hace las veces de un 
eje en torno al cual giran los cuerpos celestes con gran rigor matemático.

La gnomónica es una ciencia muy antigua. De hecho ya en el siglo XVI había poco qué decir o inventar acerca de los relojes solares, pues ese arte varias veces milenario había sido perfeccionado hasta llegar a un estado muy avanzado durante los años de la Baja Edad Media. Sin embargo, a partir del Renacimiento los fabricantes de relojes fueron lo bastante originales para darles una gran diversidad de formas, pues estaban destinados a adornar todo tipo de paredes, patios, jardines o fuentes. Los relojes solares adquirieron entonces formas insospechadas: esferas, cubos, cilindros. Inclusive llegaron a construirse relojes de sol portátiles y aun se insertaron en hermosos anillos de mano labrados. Además, y muy a tono con la época, proliferaron las inscripciones latinas grabadas en ellas que nos conminaban a emplear bien el día, cappe diem, o bien nos recordaban el señorío del tiempo sobre las cosas, tempus edax rerum. ${ }^{1}$

Las bases teóricas de la gnomónica son bastante sencillas. Un reloj solar puede ser definido llanamente como un instrumento provisto de una aguja metálica fija que arroja una sombra sobre una superficie en la que existen trazadas unas líneas, las llamadas líneas-hora. La aguja se halla colocada en el punto de convergencia de esas líneas-hora. ${ }^{2}$

A mediados del sigloXVIII el matemático francés Jean Etienne Montucla dio una definición más compleja, hecha desde el punto de vista geométrico, la cual nos permitiremos transcribir íntegra pues resulta de interés para poder describir los relojes solares construidos en México por el padre Rodríguez. Dice Montucla:

Doce planos se cortan todos en ángulos iguales sobre una misma línea. Estos planos, indefinidamente prolongados, cruzan otro plano a cierta distancia. Se trata de determinar las líneas por medio de las cuales esos planos cortan al último. Si

1 René R. J. Rohr, Sundials. History, Theory and Practice, Toronto, University of Toronto Press, 1970, p. 16.

2 Ibid., p. 44. 
hacemos que la intersección común de esos doce planos sea paralela al eje del mundo y hacemos que uno de ellos quede sobre el plano del meridiano, es obvio que entonces ellos representarán los planos de los doce círculos horarios que dividen la revolución del sol en 24 partes iguales, ya que la distancia que nos separa de ése astro es tan grande en comparación del diámetro de la tierra, que podemos, sin error sensible, considerarnos en el centro. A medida que el sol cruce por uno de esos círculos horarios, pasará también por aquel plano de entre los doce que esté situado en esa posición, y la sombra de su intersección común, que supondremos una línea opaca, se proyectará sobre la intersección de dicho plano en la superficie del cuadrante. La marcha de dicha sombra marcará consecuentemente la llegada del sol a los círculos horarios, es decir, las horas del día. ${ }^{3}$

Es fácil deducir después de esta definición que el fundamento de la gnomónica es la astronomía. Es por ello que entre los siglos XVI y XVII todos los estudiosos del arte de los relojes de sol fueron como en épocas pasadas, astrónomos. Sin embargo entre los científicos de estas dos centurias y sus antecesores existió una profunda diferencia que radicaba en el hecho de que aquéllos fueron testigos de un profundo cambio en la concepción que los hombres tenían acerca del sistema del mundo y esto fue debido en gran parte a la precisión lograda en la cronometría. En no pocas ocasiones la modernidad de los estudios astronómicos de una comunidad científica estuvo en relación directa con su pericia para construir cuadrantes solares y con el grado de precisión de estos últimos. Así, el auge de los estudios de astronomía durante el siglo XVII trajo como consecuencia un desenvolvimiento paralelo en la gnomónica. Si en la Nueva España pudieron construirse relojes de sol de gran exactitud durante ese siglo fue debido a lo avanzado de sus estudios astronómicos; aquí, como en otras partes de Europa, una gnomónica avanzada era la prueba de la asimilación de teorías científicas también avanzadas y no pocas veces heterodoxas. ${ }^{4}$

3 Jean Etienne Montucla, Histoire des Mathematiques, Paris, Henri Agasse, 1799, I, pp. 721-722.

${ }_{4} \mathrm{M}$. Saverien, Historia de los progresos del entendimiento humano en las 
Por otra parte es obvio que, a pesar de su innegable sencillez, la construcción de un reloj de sol requería de buenos conocimientos teóricos sobre la materia y, para lograr resultados óptimos, se precisaba tener aceptables nociones de cosmología -movimientos del sol, la luna y la tierra -, así como elementos de geometría descriptiva y de trigonometría. Estos requisitos distaban mucho de ser comunes a la mayoría de la población de la Nueva España en los siglos XVI y XVII, ya que aquí como en otras partes del mundo donde se cultivaba asiduamente el estudio de la astronomía, este tipo de conocimientos sólo pertenecían a un pequeño y selecto grupo de sabios. Es lógico pensar entonces que los relojes no menudeaban; ni los de sol ni los de cualquier otro tipo. No es exagerado afirmar que durante toda la época colonial el reloj más común era la salida y la puesta del sol. La vida cotidiana estaba regida por el amanecer y el anochecer. Sin embargo, para las actividades de la vida urbana que requerían de una cierta precisión en los horarios - ceremonias religiosas, cátedras universitarias, actos públicos - sabemos que en el siglo XVI se empleaban, en la mayoría de los casos, relojes de sol o bien relojes mecánicos rudimentarios de pesas, clepsidras, relojes de arena o velas de cera marcadas. La famosa "hora de ampolleta" de un vejamen universitario recuerda el uso de una simple clepsidra. ${ }^{5}$ En el siglo XVill ya se había hecho común el uso del reloj de péndulo. Además, en esta misma época la profesión de "artífice reloxero" llegó a ser respetable y lucrativa.$^{6}$

Los primeros relojes de sol construidos en México datan de mediados del siglo XVI y eran bastante rudimentarios: se

ciencias exactas y en las artes que dependen de ellas, Madrid, Antonio de Sancha. 1775 , p. 171.

5 La antiquísima invención de la clepsidra - de origen mesopotámico-se basa en el principio de que una cantidad dada de agua siempre requiere del mismo tiempo para pasar gota a gota de un recipiente a otro. Este aparato es entonces un cronómetro y no un reloj, pues marca una determinada cantidad de tiempo pero no da la hora. No ha llegado ninguna clepsidra antigua hasta nosotros. Sólo se conoce su funcionamiento por las descripciones de Vitrubio.

6 La aparición del reloj mecánico "con ruedas" no eliminó al reloj solar de inmediato ya que eran bastante imperfectos. Aunque posteriormente sí lograron desplazarlo, no deja de ser interesante que hoy en día se ha regresado -en busca de una precisión cronométrica cada vez mayor - a una forma altamente sofisticada de reloj solar, el llamado heliocronómetro. 
clavaba una varilla en la tierra y se dibujaban ciertas líneas que representaban las horas de la mañana, del medio día y de la tarde. ${ }^{7}$ Sabemos que en la segunda mitad del siglo empezaron a construirse relojes solares más precisos aunque cabe decir que su número seguía siendo reducido.

Aquí debemos hacer una observación necesaria, y es que el reloj de sol europeo trajo consigo también el modo europeo de medir el día y de contar las horas. Este fue un fenómeno relevante en el proceso de aculturación de los españoles en México. Los relojes de sol que comenzaron a fabricarse a mediados del siglo XVI ya ponen de manifiesto que un nuevo ritmo cronométrico había empezado a funcionar en la naciente sociedad novohispana. Ahora bien, ¿cómo eran esos primeros relojes de sol, construidos científicamente, que se hicieron en México? De acuerdo con el cronista dominico Hernando de Ojea, que escribía a fines del siglo XVI, eran copias de los que el célebre ingeniero Juanelo Turriăno había construido para

7 Al llegar los españoles a México descubrieron que los aztecas utilizaban de antiguo un gnomon para medir el tiempo y habian logrado una gran precisión en la determinación de los solsticios y los equinoccios. Es indudable que sus métodos tan avanzados acerca del calendario deben mucho a sus adelantos en la cronometría. El historiador Benito María de Moxó, quien escribió su obra en 1805, afirma que las observaciones astronómicas de los indios llevaron a sus compatriotas a perfeccionar su cronología. Sobre esto nos da una noticia interesante: "Estas observaciones - dice Moxó- les condujeron como de la mano a imaginar una especie de reloj solar, del que se hallaron tiempo ha muchos vestigios en el famoso cerro de Chapultepec, donde los Montezumas tenian un vistoso y ameno parque para la caza, un gran jardín de plantas para el uso de la medicina, y un suntuoso palacio o quinta para su recreo.

En una pues de las voluminosas peñas que componían dicho cerro, se descubrió en el año del 1775 un plano horizontal, en que estaban señalados de relieve y con toda precisión los puntos solsticiales, el equinoccial, y los dos polos del norte y sur. Habfa también grabada con particular inteligencia una como cinta, que tenia lugar de meridiana: de manera que era evidente que los mejicanos por medio de aquel ingenioso, aunque tosco reloj, habían logrado saber donde empiezan y acaban las cuatro estaciones del año, y donde debe fijarse el momento verdadero del medio día. Pero estas piedras que debian haberse guardado con el mayor esmero, fueron pocos días después hechas pedazos, para servir en la fábrica de ciertos hornos que se estaban a la sazón construyendo al pie de aquel mismo cerro, inutilizándose de este modo un hallazgo tan inesperado e importante, y del que los sabios de este país hubieran sacado sin duda muchas luces para aclarar una parte considerable de las antigüedades mejicanas “(Benito María de Moxó, Cartas Mejicanas, 2a. ed., Génova, Tipografía de Luis Pellas, 1839, pp. 51-52).

Acerca de los relojes solares prehispánicos y su eventual reconstrucción, puede verse: Anthony F. Aveni, Skı'watchers of Ancient México, Austin and London, University of Texas Press, 1980, pp. 20-21. 
Felipe II y los cuales gozaban de fama por su precisión y la belleza de su factura. El mismo historiador nos ha dejado un arcaico testimonio de estos primitivos instrumentos que fueron trasplantados a México pocos decenios después de la Conquista y que debieron adornar las fachadas de las principales iglesias o los edificios públicos. ${ }^{8}$ Sin embargo no fue esa la única fuente donde se inspiraron los "aritméticos"que intentaron construir relojes solares. Conocían los textos clásicos de la antigüedad acerca del tema, sobre todo Vitrubio, y los de los autores de su época, básicamente Oroncio Fineo y Cristóbal Clavio. No sería sino hasta la tercera década del siglo XVII que se elaboraría en México todo un tratado de gnomónica, hecho por el que entonces ocupaba la cátedra de matemáticas en la Real y Pontificia Universidad el constructor del bello reloj de sol del Convento de Santo Domingo de Oaxaca, el padre Diego Rodríguez.

Varios fueron los motivos que impulsaron a fray Diego a redactar ese voluminoso manuscrito destinado a los relojes de sol y en forma colateral a otro tipo de instrumentos astronómicos. En primer término, el deseo de contar con aparatos confiables para sus propias observaciones astronómicas; después, su interés en calcular con precisión las coordenadas de la ciudad de México y por extensión las de los principales puertos y ciudades del virreinato; y por último, su intención de dotar a los novohispanos de relojes precisos para sus labores cotidianas. Estos relojes debían construirse tomando en consideración la posición geográfica exacta de los lugares en que iban a ser utilizados, de ahí el empeño reiterado de este astrónomo mexicano en determinar con precisión dichas coordenadas y las largas explicaciones que en su escrito destinó a este fin.

La obra lleva el título siguiente: Tratado del modo de

* Hernando Ojea, La venida de Christo y su Vida y' Milagros en que se concuerdan los dos testamentos divinos, Viejo y Nuevo, En Medina del Campo, por Christobal Lasso Vaca, Familiar e impresor del Santo Oficio, 1602, f. 33v. Ojea era gallego y pasó a México donde fue cronista de la Orden de Predicadores. En esta obra trata diversos asuntos referentes a la conquista y colonización del Nuevo Mundo, principalmente de México. 
fabricar reloxes horizontales, verticales, orientales, etc. Con declinación, inclinación, o sin ella: por senos rectos, tangentes, etc. Para, por vía de números, fabricarlos con facilidad. Consta de 145 folios y ha quedado manuscrita. ${ }^{9}$ Aunque posee una unidad temática notable en la que, a diferencia de los tratados similares de.la época, hay poco lugar para las digresiones, la obra puede dividirse en once secciones. De la primera a la cuarta parte se exponen los aspectos teóricos de la gnomónica, de la quinta a la novena están destinados a la técnica de construcción de los relojes de sol (incluida una descripción del que envió a Oaxaca) y las dos últimas secciones abordan un problema concreto: el cálculo de dos eclipses acaecidos en los años de 1638 y $1641 . .^{10}$ La obra fue redactada a lo largo de varios años y probablemente es el borrador de un texto más grande al que fray Diego denomina en repetidas ocasiones "nuestro cartapacio de marca mayor"," que posiblemente tenía destinado para la imprenta y que, como todas sus obras matemáticas, permaneció inédito o bien se perdió. ${ }^{12}$ Así nos lo hace ver cuando nos dice: “Advierto que aquí no hubo estilo ni método, porque este tratado fue sólo para hacer memoria para conmigo mismo, hasta que en mejor ocasión se disponga cómo ha de estar".

Los autores que consultó para elaborar su obra no son numerosos pero sí los más representativos de su época sobre ese tema. En primer lugar está el jesuita Clavio, autor de una Gnomónica dividida en ocho libros publicada en 1581 y que le dio gran celebridad. ${ }^{13}$ Este voluminoso y confuso texto así

9 Conservado en la Biblioteca Nacional de México, Sección de Manuscritos, Signatura: MS. 1521.

10 Las secciones segunda y tercera parte están invertidas seguramente por un error de encuadernación. La segunda porta el título "Tercer Cuaderno" y la tercera "Segundo Cuaderno".

1 Debió ser un manuscrito voluminoso pues al citar los folios de referencia nos damos cuenta que sobrepasaban los 400 folios. Este perdido "original" de relojes de fray Diego, al que cita como "nuestro cartapacio" estaba, según su descripción, bellamente encuadernado en piel.

12 Elias Trabulse. "Un científico mexicano del siglo xill: fray Diego Rodríguez y su obra"en ElCírculo Koto. México. Fondo de Cultura Económica -Secretaría de Educación Pública, 1984, pp. 40-45 (Lecturas Mexicanas, 54).

13 Dice Montucla refiriéndose a Clavio que fue uno de los científicos del siglo wi que gozó de mayor celebridad (Histoire des Mathematiques, I. p. 586). En efecto 
como el tratado del Astrolabio del mismo autor fueron leídos con cuidado por fray Diego. Toda la primera parte de su manuscrito está prácticamente destinado a comentar, y no pocas veces a corregir, a Clavio, de quien dice que trató el tema "con poca claridad" y dejando en el tintero muchos puntos que debió exponer. Incluso llegó a calificar su obra de "libro atrasado de relojes". A pesar de esta crítica que otros autores europeos compartían con nuestro mercedario es evidente que fue Clavio quien le proporcionó las trece reglas fundamentales de la teoría de los relojes de sol que fray Diego expone en la primera parte de su obra. El segundo autor a quien acudió, con menos crítica y más benevolencia, fue Oroncio Fineo de quien dice haber utilizado su obra De solaribus horologiis ${ }^{14}$ para la construcción de sus propios relojes de sol. En efecto tanto los relojes mayores -entre los que se encuentra el de Oaxacacomo la curiosa sortija con reloj solar que se fabricó para su uso particular, están copiados de los modelos que en bellos grabados aparecen en la obra de Fineo. ${ }^{15}$ Otros autores también citados fueron Andreas Schöner, geómetra del siglo XVI, uno de los primeros en abordar los aspectos teóricos de la gnomónica; Adrián Metio de quien tomó los métodos para afinar el cálculo de las latitudes; Johannes Stoeffer, astrónomo de principios del siglo XVI cuyas Tablas de posiciones estuvieron muy en boga y fueron utilizadas por cosmógrafos y navegantes; Antonio Magini, autor favorito de fray Diego quien gustaba de discutir sus tesis astronómicas y era afecto a utilizar sus Tablas que consideraba muy exactas. Por último, cabe mencionar a John Neper, el descubridor de los logaritmos. Fray Diego lo mencionó en repetidas ocasiones, sobre todo cuando elaboró sus propias Tablas logarítmicas de funciones

Clavio fue un autor enciclopédico que abarcó todos los conocimientos matemáticos de su tiempo. Sus comentarios a Euclides y a Sacrobosco y sus tratados de Gnomónica y sobre el Astrolabio pero sobre todo sus escritos acerca de la reforma al Calendario prueban esa afirmación. Nació en Bamberg en 1538 y murió en Roma en 1612. Sus obras forman cinco gruesos volúmenes en folio y aparecieron en 1611 .

14 Oronce Finé, De solaribus Horologiis el Quadrantibus libriquator, Paris, Gughielm Cavellat, 1560. Esta obra forma parte de la célebre Prothomathesis del mismo autor. Fray Diego conoció la edición italiana de 1587 cuya última parte trata de los relojes de sol.

is Orontio Fineo, Opere, In' Venetia, presso Francesco Franceschi Senese, 1587,

De gli oriuoli et quadranti a sole. 
trigonométricas. Estos autores $-\mathrm{y}$ otros más que no mencionamos - dan cumplida cuenta de la erudición científica de fray Diego, quien estaba al tanto de los avances europeos más recientes en matemáticas. Sin embargo, debemos puntualizar que todo ese acervo bibliográfico no resta originalidad al tratado de gnomónica de nuestro mercedario, quien no sólo se permitió criticar y corregir a varios de dichos autores sino que planteó y resolvió diversos y novedosos problemas referentes a las bases teóricas y a la construcción de relojes de sol que aquéllas no habían tratado $y$, aunque a veces acepta de buen grado las técnicas de diseño europeas - sobre todo las propuestas por Fineo-, es claro que había que adaptar esos aparatos a la posición geográfica de México, y también en esto el padre Rodríguez debía seguir sus propios cálculos.

El método de exposición que Fray Diego siguió en su obra y los recursos matemáticos a los que recurrió -entre otros el uso de logaritmos - revelan la originalidad de este denso y difícil tratado. El mismo se encargó de resumir cuáles fueron sus criterios para escribirlo. Estas son sus palabras:

Para tratar, pues, aquí esta materia con claridad y generalidact de suerte que quede entendida y con inteligencia de algunos círculos del cielo que son los que se representan en líneas rectas en los planos o paredes, con otras figuras que llaman elipses, parábolas e hipérboles, que dimanan de las figuras cónicas en sus secciones, hemos de ponerlos en demostración en el mismo cielo para deducir de allí los ángulos y líneas en los planos, y éstos con alguna generalidad que comprenda todos los accidentes referidos, y primero de los más regulares y fáciles para después pasar a los más irregulares y no tan fáciles que es el orden que siempre se debe guardar valiéndonos en todo de la trigonometría, que es el alma de las matemáticas y' el único refugio de los matemáticos, y para mayor facilidad por via de logaritmos, aunque no excusaré los senos, tangentes y secantes donde conviniere, para que los más entendidos en estas materias los usen y manejen, obrando asimismo por geometría la mayor parte de ellas, $y$ aun formarlos por diversos modos para que cada uno elija el que más le agradare y el que más conviniere, fuera de que será necesario así para verificarlos y no cometer yerros que en las líneas y divisiones de círculos se cometen muy fácilmerte, en que suele haber mucha confusión 
por las muchas líneas, la pequeñez del papel en que se obra y otros accidentes en las reglas y compases, que es necesaria mucha maña y curso para obrarlos con perfección. Por todo lo cual siempre aconsejaría yo se valiesen de la trigonometría y sus números, formando tablitas en que hay más certidumbre y menos embarazo de líneas, que es lo principal que ejecutaremos después de los modos geométricos, para la inteligencia que se pretende, y aunque esta materia es larga y muy dilatada, excusaremos demostraciones. ${ }^{16}$

Establecido el método, fray Diego pasa a explicar en qué consiste la gnomónica y cuáles son sus principios:

La materia de relojes de sol no es otra cosa que una artificiosa perspectiva con que los círculos horarios del cielo y demás círculos de él, así máximos como los menores, se demuestran un los planos o paredes, así perpendiculares al horizonte como inclinados, con la variedad de inclinaciones al meridiano y a otros círculos, de tal suerte que demuestren perfectamente lo mismo que [sucede] en el cielo 17

De ahí pasa nuestro matemático a enumerar los diferentes relojes de sol que se pueden construir, sean con declinación o sin ella:18 horizontales, verticales, orientales, occidentales y polares. Asimismo distingue los relojes "estables" o fijos de los "portátiles"; los primeros destinados a un lugar único y a una latitud particular; los segundos adaptables a cualquier latitud. Sus explicaciones acerca de los relojes ecuatoriales ${ }^{19}$, horizontales $^{20}$ y verticales ${ }^{21}$ son muy amplias debido a que fueron los

16 Fray Diego Rodriguez, Tratado del Modo de fabricar Reloxes (MS), f 133 v. (Las cursivas son nuestras).

17 lbid., t. 133 r.

18 Se denominan relojes no declinantes los que están orientados del este al oeste. Su carátula mira entonces exactamente al sur o al norte. Si está orientado al sur se llama meridional, y si al norte es septentrional. Los relojes declinantes los que miran exactamente al este o al oeste, o sea que su declinación es de $90^{\circ}$ exactamente; se les llama orientales y occidentales respectivamente.

${ }_{19}$ Cuando la base plana del reloj es perpendicular al gnomon, entonces eso quiere decir que también es perpendicular al eje de la tierra y en consecuencia paralelo al ecuador. Este es un reloj ecuatorial.

20 Los relojes horizontales son aquellos en que el gnomon está fijo al cuadrante en un ángulo igual a la latitud, siempre y cuando la base sea horizontal. Si se tirase una línea vertical desde la punta del gnomon hacia la base, esa sería la línea del mediodía siempre y cuando esté perfectamente orientada en la dirección norte-sur.

${ }_{21}$ Un reloj vertical es aquel que puede adoptar cualquier tipo de orientación (a 
que él construyó. Inclusive dedicó varias páginas a estudiar los relojes de luna, lo que le permitió explicar las fases lunares, los ángulos de nuestro satélite respecto del sol y cómo podía ser leída la hora en un reloj de este tipo por la simple adición del tiempo indi zado por la sombra lunar en el cuadrante más al ángulo lunar expresado en horas. Para determinar este último valor elaboró una serie de tablas de conversión y señaló los márgenes de error en cada caso.

Todos los teóricos de la ciencia de los relojes de sol de los siglos XVI al XVIII coincidieron en señalar que la principal dificultad -en realidad la única de importancia - en la construcción de esos instrumentos radicaba en la determinación de la elevación del polo sobre el plano del cuadrante, o sea la latitud y el meridiano del lugar, es decir, la latitud. ${ }^{22}$ Fray Diego no fue la excepción, de tal manera que una gran parte de su tratado la destinó a discutir los métodos para obtener esos valores. Indicó que para que la sombra del gnomon de un reloj solar - sea horizontal o vertical - caiga a las doce horas del día sobre el meridiano del lugar debería tener un ángulo con respecto al plano horizontal igual al valor -en grados - de la latitud de la localidad donde se encontraba el reloj, de ahí la importancia de obtener ante todo este último valor. Una serie de cálculos hechos a lo largo de varios años le permitieron fijar con exactitud esa coordenada de la ciudad de México en $19^{\circ} 15^{\circ}$. La longitud resultaba más díficil de obtener y sólo fut determinada satisfactoriamente después de que observó los eclipses de 1638 y 1641 . Para determinar ambas coordenadas presumiblemente utilizó varios relojes y cotejó las lecturas hechas en forma simultánea. Además acostumbraba afinar sus resultados combinando tres tipos de cálculos: el hecho a base

diferencia del ecuatorial y del horizontal). Cuando se le orienta hacia el sur sè le llama meridional (como el reloj de Oaxaca de fray. Diego) y cuando se orienta al norte se le llama septentrional. Al oeste y al este se le denomina occidentales y orientales' respectivamente.

22 Una definición sencilla de "latitud" sería: el ángulo que forma un punto $X$ situado en la superficie de la tierra con respecto al centro de la tierra y al plano ecuatorial. Y la "longitud" es la diferencia medida en grados entre el meridiano y un punto de referencia u origen. Puede ser medido desde el este o el oeste y sus valores van de $0^{\circ}$ a $180^{\circ}$. 
de tablas previamente calculadas, el rigurosamente trigonométrico y el que aplicaba los logaritmos.

Los eclipses de 1638 y 1641 llenaron una doble función ya que no sólo ayudaron, como ya dijimos, a determinar la longitud sino que además permitieron que fray Diego emprendiera la construcción de una serie de aparatos astronómicos calibrados de acuerdo con las necesidades de los diversos puntos del virreinato donde iban a ser utilizados - uno de ellos fue el reloj de Oaxaca.

El eclipse de luna del 20 de diciembre de 1638, debidamente reseñado al final de su manuscrito sobre relojes, nos da una idea clara del modus operandi de fray Diego. ${ }^{23}$ Ahí percibimos la complejidad de una observación astronómica en el siglo XVII, que por lo general debía ser hecha por varias personas con diverso instrumental. En este eclipse fray Diego contó con la ayuda del médico Gabriel López de Bonilla y probablemente de algunos discípulos suyos. Según nos dice, utilizó varios relojes ajustados al polo de la ciudad de México y un telescopio, y se auxilió con tablas astronómicas de autores reconocidos como Kepler, Magini, Tycho Brahe, ${ }^{24}$ Langomontano y Lansberg. Sus puntos de relación fueron Venecia, Graz, Hveen. Uranibourg, Franckfurt y Roma. Después de tomar como punto de referencia para sus mediciones a la estrella Aldebarán, resume sus primeras estimaciones de la siguiente manera:

el principio de la total obscuración fue a las 6 horas 37 minutos de la tarde del tiempo aparente, que concuerda con la hora que entonces advertí en todos los relojes de México que andaban buenos.

\section{Y añade:}

siendo las 8 horas 13 minutos de la noche el principio de la recuperación, será toda [la duración] de una hora 36 minutos, y

23 Hemos descrito esta observación astronómica en nuestro estudio titulado: "Fray Diego Rodríguez y la posición geográfica de México", Diálogos 106, julioagosto 1982 ; pp. 13-15.

24 Cita las Tablas de David Origano basadas en las de Tycho Brahe. 
su mitad 48 minutos, que añadidos a las 6 horas 37 minutos del principio de la obscuración, fue - - su mitad - a las 7 horas 25 minutos, tiempo aparente de la conjunción verdadera que buscamos, que restado del tiempo aparente del cálculo que es de 15 horas 16 minutos quedan, por diferencia de meridianos, 7 horas 51 minutos de México a Franckfurt que es la que buscamos; y está tan concordante que David Origano pone por mitad exacta de la obscuración 46 minutos 23 segundos, y por la observación hallamos 48 minutos que aun no son 2 minutos de diferencia. Con que quedará aún asentado ser esta la diferencia de meridianos de México a Franckfurt y quitando 11 minutos solos quedan 7 horas 40 minutos por diferencia de México a Hafnia en Dania ${ }^{25}$ y añadiendo 6 minutos a este tiempo serán 7 horas 46 minutos de diferencia entre México y Venecia que son las tres que buscamos hasta que por otro eclipse se perfeccione esto.

Este nuevo fenómeno que le permitió afinar sus cálculos fue el eclipse de sol de 9 de mayo de 1641, que un discípulo suyo, Francisco Ruíz Lozano, observó en Lima. Este astrónomo peruano había estudiado en México con fray Diego y llegó a ser el cosmógrafo mayor del virreinato del Perú, catedrático de matemáticas en su célebre universidad y profesor de pilotos y navegantes. Era asiduo corresponsal de nuestro mercedario "porque siempre lo reconocía por su maestro, y como a tal le enviaba a consultar algunas materias que allá se le ofrecían". ${ }^{26}$ Una de estas consultas hecha en estrecha colaboración científica entre ambos fue la del eclipse antes mencionado. Fray Diego, apoyado en los valores que obtuvo en 1638, calculó con antelación el de 1641. Le indicó a Ruíz Lozano que se iniciaría a las 11 horas 45 minutos 5 segundos y que tendría una duración de 5 horas 20 minutos 52 segundos. Asimismo le señaló la hora precisa del eclipse total: las 15 horas 14 minutos 27 segundos y 3.3 décimas, hora de Lima. Asimismo determinó la posición geográfica de esta ciudad a la cual le asignó una longitud de 6 horas 25 minutos al occidente de Venecia y una

25 Hveen-Uranibourg en Dinamarca.

26 rray Francisco de Pareja, Crónica de la Provincia de la Visitación de Nuestra Señora de la Merced redención de cautivos de la Nueva España, México, Imprenta de J.R. Barbedillo, y Cía, 1882. II, p. 247. 
latitud de 12 grados 30 minutos. La distancia de México a Lima la estimó en una hora 21 minutos. Sus cálculos son de un rigor notable, hasta el punto de que se permitió corregir el célebre Regimiento de Navegación de García de Céspedes, obra consultada asiduamente por los navegantes españoles en sus viajes por el Atlántico y el Pacífico. Este autor le había fijado a la distancia entre Lima y México un valor de una hora 34 minutos. Al final de sus cálculos fray Diego dibujó un esquema del fenómeno, y le puso el título de Typus Eclipsis. Ahí se marcaba la posición de la capital peruana, lo que permitió que Ruíz Lozano estuviera en posibilidad de determinar a su vez las coordenadas geográficas de los lugares más importantes del litoral de ese reino: puntas, puertos, cabos y algunos sitios del interior. Nada de esto hubiera podido ser realizado sin los datos que le proporcionó fray Diego. ${ }^{27} \mathrm{~A}$ su vez el astrónomo peruano le envió a éste sus observaciones del eclipse, lo que le permitió a nuestro mercedario afinar aún más sus cálculos de 1638 y - sobre todo-le abrió la posibilidad de iniciar la construcción de instrumentos astronómicos de gran precisión.

A lo largo de su vida fray Diego fue un incansable artífice de instrumentos científicos, ésta parece haber sido una de sus actividades favoritas. Su biógrafo fray Francisco de Pareja afirmaba que poseía "muchos instrumentos matemáticos y astronómicos que con sus propias manos fabricaba en su celda, así de astrolabios muy curiosos, como de arcos de perspectiva y globos, todo con grandísima curiosidad". ${ }^{28} \mathrm{En}$ efecto, su celda en el bello convento de La Merced - como las de algunos de sus contemporáneos o como las que años más tarde tendrían Sigüenza y Góngora o Sor Juana - debió estar llena de aparatos científicos, libros, mapas y apuntes personales. Para darnos una idea de lo que debieron contener eso

27 Gerardo Ramos, "El desarrollo de la matemática en el Perú", en: Ernesto Yepes (editor). Algunos aportes para el estudio de la Historia de la Ciencia en el Perú, Lima, Concytec, s/f, pp. 15-16. Ruíz Lozano fue protegido del virrey Conde de Alva de Aliste y gozó de una buena posición en su patria como profesor de matemáticas. Escribió un Tratado de Cometas.

${ }^{28}$ Pareja, loc. cit. 
gabinetes de trabajo, podemos acudir a diversos testimonios de esa época. Uno de ellos es el inventario de los bienes de un astrónomo e impresor, amigo de fray Diego y autor comoél de libros sobre cometas y meteoros, llamado Juan Ruyz, hijo del célebre Enrico Martínez. Dicho inventario, realizado el $17 \mathrm{de}$ agosto de 1675 , poco tiempo después de su muerte, nos revela no sólo una rica biblioteca científica donde figuraban clásicos de la ciencia mexicana tales como Juan de Barrios, Cepeda y Carrillo, Diego García de Palacios y Enrico Martínez, sino también libros de autores europeos, muchos de ellos utilizados por fray Diego, a saber: Stoeffler, Fineo, García de Céspedes, Magini, Sacrobosco, Regiomontano, Chávez, Apiano, Zamorano y Porter de Casanate. Asimismo menudeaban lunarios, pronósticos y almanaques ya que Ruyz -como el padre Rodríguez - era autor de ese tipo de obras. ${ }^{29}$ En cuanto a los aparatos científicos, había globos celestes y terrestres, relojes, compases de bronce y acero, imanes, astrclabios de bronce y de madera. 30

No muy diferentes debieron ser los gabinetes de Sigüenza y de Sor Juana. El del primero poseía diversos instrumentos matemáticos, algunos de gran valor, así como telescopios y esferas armilares, ${ }^{31}$ y el de la segunda sabemos que poseía instrumentos musicales y matemáticos, "que los tenía - dice su primer biógrafo- muchos, preciosos y exquisitos". 32

Fray Diego dedicó muchas págınas de su obra sobre los relojes a exponer los métodos de construcción de instrumentos astronómicos. Una sección completa la destinó al estudio del astrolabio, basada en buena medida en el tratado que sobre este instrumento había escrito el jesuita Clavio. Muchos folios

29 José Miguel Quintana, La astrología en la Nueva España en el siglo XVil, México, 1969, pp. 47-65

30 Francisco Salazar, "Dos familias de impresores mexicanos del siglo Xviı", en Memorias de la Sociedad Científica Antonio Alzate, tomo 43, (1924), México, 1925, pp. 502-507.

31 Carlos de Sigüenza y Góngora, Testamento, en: Francisco Pérez Salazar, Biografía de D. Carlos de sigüenza y Góngora seguida de varios documentos inéditos. México, Antıgua Imprenta de Murguía, 1928, p. 172: Irving A. Leonard, Don Carlos de Sigüenza y' Góngora. Un sabio mexicano del siglo XVII, México, Fondo de Cultura Económica, 1984, p. 187.

32 Diego Calleja, S.J., Vida de Sor Juana, Arotaciones de E. Abreu Gómez, México, Antigua Librería Robredo, 1936, p. 38. 
están cubiertos de figuras y diagramas de este interesante aparato de medición, del que analizó en detalle los aspectos teóricos. Lamentablemente pocos de estos instrumentos utilizados en la Nueva España han sobrevivido hasta hoy. ${ }^{33}$ También estudió - y tenía en su celda - esferas armilares, es decir, esa representación a base de anillos de la esfera celeste. Estas últimas eran muy codiciadas y cuando portaban la firma de un astrónomo de renombre su cotización llegaba a ser muy alta. Para darnos una idea del gran aprecio en que se las tenía conviene que transcribamos un largo párrafo donde el cronista dominico Hernando de Ojea, antes citado, nos describe la que Juanelo Turriano construyó para Felipe II y que fue el pasmo de sus contemporáneos. También aquí menciona la sortija con un reloj de sol que el monarca portaba. El testimonio es interesante para ilustrar el tipo de instrumentos que nuestro mercedario construía y utilizaba. Dice el historiador Ojea:

Quando un artífice es muy diestro en su arte, por grande que sea la cosa, la sabrá reducir a muy pequeño espacio. Así lo vemos cada día en los Escultores de imágenes, de sellos y de pincel: que en una pequeña piedra preciosa, o en un pequeño metal, pintan y esculpen imágenes de Gigantes, caballos y animales grandes, y otras mil figuras y machinas grandísimas. Testigo es también desto aquel famoso relox que trae en el dedo, en el hueco de la pied ra de un anillo, y del tamaño de una uña, nuestro Catholico Rey Philipo de España que hizo en nuestros tiempos el famosísimo mathematico, grande astrólogo y excelente artífice Juanelo Turriano Cremonense, y el otro mayor que hizo el mismo en forma de Esphera, o quasi de dos pies de diámetro o poco menos, que tiene mil y ochocientas ruedas con todos sus adherentes. En el qual con maravilloso artificio se ven y se descubren por los costados de él, no solamente las horas del sol y de la luna sino también los movimientos que en las nueve o diez Espheras del cielo hallan y consideran los Astrólogos, por menudos, diferentes y contrarios que sean y todo ello por sus años, meses. días y horas. Allí se muestra el primer moble con

33 Un interesante y bien documentado estudio acerca de un valioso astrolabio del siglo xvı que ìe utilizado en México y que ahora se conserva en el Museo Nacional de Historia del Castillo de Chapultepec, es: Miguel Angel Fernández Villar, Sobre el Astrolabio firmado por G. Frisius y G. Arsenius, México, INAH, 1976. 
su movimiento natural, de Oriente a Poniente, el de la octava Esphera y de los siete planetas inferiores con su movimiento natural de Occidente al Oriente; el rápido o violento de ellos con sus trepidaciones. $Y$ juntamente los doce signos del Zodiaco. $Y$ otras muchas estrellas principales y conocidas con todas sus diversidades, conjunciones y apariciones. $Y$ todo $y$ cada casa de por sí a sus pasos diferente. El primero móvil en un día, el cielo estrellado en treinta años, Júpiter en doce, Marte en dos, el Sol en uno, Venus en trescientos y cuarenta y ocho días, Mercurio en trescientos y treinta y ocho, y la luna en un mes. También aquella Esphera que hizo de vidrio el ingeniosísimo y gran Mathematico Archimedes a semejanza del octavo cielo, con muchas estrellas y figuras puestas en conveniente distancia por medidas y regla cierta de sus apartamientos verdaderos. $Y$ dentro de esta Esphera otras siete Espheras o bolas menores tocantes las unas en las otras a imitación de los siete planetas, las quales hacía mover de suyo cabalmente sin haber error en los mismos puntos y movimientos que se mueven los celestiales. Con lo qual se descubrían a sus tiempos los ayuntamientos y contrariedades, aspectos y proporciones que las estrellas tienen con los planetas y los mismos planetas entre sí. ${ }^{34}$

Según propia confesión, fray Diego construyó por encargo por lo menos una docena de relojes mayores de sol. Entre ellos había cuatro que eran verticales meridionales y con declinación. Asimismo diseñó varios relojes y otros instrumentos científicos para enviárselos a Perú a su discípulo Ruíz Lozano a quien también le envió un grueso manuscrito, hoy perdido, acerca del uso de los logaritmos para que allá se diera a la imprenta ya que ni en la Nueva ni en la vieja España había logrado que se imprimiera. ${ }^{35}$ Asimismo parece haber construido un reloj de péndulo, sin embargo esto fue una excepción ya que fueron los de sol los que más absorbieron su interés. Para sí mismo construyó también varios. Uno de ellos - seguramente el que le parecía más exacto- fue descrito en detalle en un capítulo de la tercera parte de su obra sobre relojes. ${ }^{36}$ Ahí estudió ese aparato que sabemos que estaba

${ }^{34}$ Ojea, op. cit., ff. $260 \mathrm{r}-\mathrm{v}$.

35 Pareja, op. cit., II, p. 248.

36 Fray Diego Rodríguez, Tratado del modo de fabricar reloxes (MS), ff. 29 r-32 v y 127 r. 
colocado en el lado derecho de la ventana de su celda "mirada desde la calle y no de dentro". Por sus descripciones sabemos que esa ventana estaba orientada al noroeste. El reloj había sido calculado a la altura de México y era tanto de sol como de luna ya que fray Diego se preocupó de marcar las posiciones precisas del gnomon al mediodía y a la medianoche. Asimismo elaboró una compleja Tabla de horas acotada cada diez días a efecto de obtener lecturas cada vez más precisas en su propio reloj. Porta el sugestivo título: Mexicanae civitatis cuius artica subestimatio est $19^{\circ} 15^{\prime}$ pro 20 anno post bisextilem et sol in meridiano secundum Tichonem. ${ }^{37}$ También poseía en su celda un reloj de luna de dimensiones menores comparado con el anterior, que menciona sólo ocasionalmente.

Otro tipo de relojes que le interesaban en sumo grado eran los portátiles de mano. Como ya dijimos tomo la idea y el método de construcción de Oroncio Fineo y se construyó para sí una sortija idéntica a la descrita por este autor. ${ }^{38}$ Estos anillos eran por lo general de oro o de plata. No podían ser muy gruesos. Sus ángulos debían ser hechos a escuadra. Su forma era la de un rectángulo alargado, dividido por tres líneas que lo cortaban a lo ancho. El lado inferior del rectángulo era la línea equinoccial y el superior la del trópico. Una serie de líneas inclinadas que atravesaban ese rectángulo señalaban las doce horas. Un par de orificios abiertos en los extremos permitían la entrada de un rayo de sol que señalaba la hora. El rectángulo metálico se cerraba entonces hacia adentro juntando sus dos lados menores. "Adviértase - dice fray Diegoque al cerrar el anillo las horas han de quedar señaladas por la parte de adentro y no por la parte de afuera". En efecto, era necesario quitárselo para saber la hora y colgarlo de un "suspensario" vertical que lo sujetara junto a los orificios. Entonces el rayo de sol que penetraba por uno de ellos marcaba la hora. El orificio del lado izquierdo la señalaba entre el 21 de septiembre y el 21 de marzo, y el del lado derecho entre el 21 de marzo y el 21 de septiembre, es decir, corría de un lado a otro según los equinoccios de primavera y otoño, acorde con el recorrido

${ }^{37}$ Ibid., f. 58 r. Vćase también el f. 79 r.

${ }^{38}$ Fineo, op. cit., ff, $46 \mathrm{r}-49 \mathrm{v}$. 
aparente del sol en el horizonte. Según fray Diego no sólo podía utilizarse como anillo de mano, sino también como brazalete o de cualquier otra forma que pudiera ser fácil y cómodo de llevar consigo. ${ }^{39}$

Solamente uno entre los muchos relojes construidos por el padre Rodríguez ha llegado hasta nosotros, de ahí nuestra afirmación de que se trata de un invaluable testimonio para la historia de la ciencia en México. Su historia es bastante singular ya que mientras los relojes y aparatos que poblaban su celda sufrieron los avatares que aquejaron el convento de la Merced durante los últimos doscientos años y se perdieron irremisiblemente, el antiguo reloj de sol de Oaxaca sobrevivió hasta nosotros casi intacto.

$\mathrm{Su}$ origen tiene que ver con el establecimiento de la orden mercedaria en Oaxaca, la cual desde el año 1601 - o sea, recién establecida en la capital virreinal- buscó fundar conventos en Puebla' y Oaxaca con el fin de que ambos "fuesen hospicio donde los religiosos que pasaban de Guatemala a México tuviesen dónde descansar de camino tan largo".40 Con gran empeño los mercedarios persiguieron este designio y lograron la aprobación tanto del virrey, a la sazón el conde Monterrey como de la Real Audiencia así como la concesión final del Consejo de Indias con la Real Cédula correspondiente. La orden designó para fundarla a fray Baltasar Camacho, quien con gran tenacidad había logrado establecer el de Puebla "y porque su gran talento - dice el cronista de la orden- sabía aplicar la maña para conseguir cualquier fin". En efecto, con gran habilidad diplomática para llevar a cabo una empresa de suyo difícil, el padre Camacho logró la aprobación de los dos cabildos oaxaqueños, pero sobre todo fue beneficiario del apoyo casi ilimitado que le brindó el entonces obispo de la vieja

39 Sabemos que Fray Diego obsequió uno de estos relojes de brazalete finamente tallado en pląa a la virreina marquesa de Mancera, esposa de su amigo y protector y además aficionado a la astronomía y a la astrología el Marqués de Mancera.

40 La calle del Relox en Oaxaca llevó ese nombre hasta 1884. Hoy en día se Jenomina del Cinco de Mayo. 
Antequera, el dominico fray Bartolomé de Ledesma. El crecimiento y progresos del convento mercedario de Oaxaca que comenzó por ser una modesta ermita hasta convertirse en una bella construcción del siglo XVIII debe mucho a la estrecha colaboración que siempre existió entre la orden dominicana y la de Nuestra Señora de la Merced, y esto tiene su origen en la buena disposición del obispo Ledesma. Así, cuando fue establecida una cátedra de filosofía para "los hijos de la ciudad", la orden de Predicadores y el obispo pidieron que el titular fuera un mercedario. Aparentemente la costumbre de que ese puesto recayera siempre en un miembro de esta orden religiosa se conservó a todo lo largo del siglo XVII.

No es de extrañar entonces que cuando los dominicos festejaran la apertura de la puerta sur de la iglesia de su nuevo y suntuoso convento, los mercedarios se apresuraran, no sabemos si a petición expresa de aquéllos, a hacerles un singular obsequio tan útil como valioso para adornar esa parte del edificio, así que demandaron un reloj solar al matemático de la orden. Ese reloj debió ser colocado originalmente en el costado sur de la iglesia, probablemente adosado a la bella fachada lateral que da a esa calle antiguamente llamada la calle del Relox que "baja muy dilatada al cuerpo de la ciudad", como dice el cronista dominico fray Francisco de Burgoa. ${ }^{40} \mathrm{Y}$ ahí quedó hasta que fue trasladado al claustro del convento, donde actualmente se halla. ${ }^{41}$

En diversos pasajes de su obra manuscrita sobre relojes fray Diego alude al reloj que envió a Oaxaca. Incluso una breve sección la destina a explicar cuál fue el método que siguió en su construcción y ahí mismo incluye una valiosa Tabla de las alturas del sol sobre el horizonte adaptadas a la posición geográfica de Oaxaca. ${ }^{42}$ Es un hermoso reloj vertical-

41 Hoy en el Museo Regional de Oaxaca. Sobre la iglesia y el convento, véase: Fray Esteban Arroyo, O.P., El monumental convento de Santo Domingo de Oajaca. Oajaca. México, 1955.

42 Guaxaca 180 30'. Tabla de las alturas del sol sobre el horizonte, longitudes de las sombras en 100 partes, el gnomon por tangentes y' los grados de latitud para el relox horizontal en $18^{\circ} 30^{\prime}$ de polo septentrional en: Fray Diego Rodríguez, Tratado del Modo de fabricar Reloxes (MS), f. 125 r. 
meridional, ${ }^{43}$ y no fue poco el trabajo que le costó calcularlo y hacer que se grabara en piedra. Para lo primero pudo utilizar sus datos del eclipse de luna de 1638 que a todas luces le fueron de gran valor, para lo segundo contó con un hábil maestro de labrado en piedra - probablemente de entre sus amigos canteros de la catedral metropolitana-, el cual siguió exactamente sus instrucciones.

El reloj está esculpido en una pesada lápida de basallo de 1.73 metros de alto por 0.74 metros de ancho. Carece de gnomon y sólo queda el orificio que ocupó. En la parte inferior tiene grabado: "Año 1639". La parte superior derecha y la inferior izquierda muestran fracturas en la piedra. La línea de la eclíptica corta las líneas horarios en ángulo recto. El gnomon se halla a $32 \mathrm{~cm}$ del borde superior y obviamente a $37 \mathrm{~cm}$ de cada lado. Las líneas-hora van del 5 al 12. Fray Diego se preocupó en dejarnos en su obra de gnomónica un dibujo de su reloj ${ }^{44}$ y diversos esquemas con sus medidas ${ }^{45}$ que coinciden plenamente con lo ejecutado en la piedra. Ambos son testimonio de su capacidad como científico, y ambos afortunadamenie han llegado hasta nuestros días.

43. El reloj fue adosado verticalmente a la portada sur de la iglesia de Santo Domingo. Por tanto era un reloj vertical meridional, ya que estaba orientado hacia el sur. Véase; supra, nota 21 . En repetidas ocasiones fray Diego dijo que el reloj que envió a Oaxaca era vertical-meridional ya que era obvio que sabía que estaba destinado a la portada sur de la iglesia.

44 Ibid., f $126 \mathrm{r}$.

45 Ibid., f. 126 v-127 r, 132 r. (hoja anexa sin paginación). 